\title{
Melatonin and Nitrones As Potential Therapeutic Agents for Stroke
}

\author{
Alejandro Romero ${ }^{1 *}$, Eva Ramos ${ }^{1}$, Paloma Patiño ${ }^{2}$, Maria J. Oset-Gasque ${ }^{3}$, \\ Francisco López-Muñoz ${ }^{4,5}$, José Marco-Contelles ${ }^{6 *}$, María I. Ayuso ${ }^{7}$ and Alberto Alcázar ${ }^{8}$ \\ ${ }^{1}$ Department of Toxicology and Pharmacology, Faculty of Veterinary Medicine, Complutense University of Madrid, Madrid, \\ Spain, ${ }^{2}$ Paediatric Unit, La Paz University Hospital, Madrid, Spain, ${ }^{3}$ Department of Biochemistry and Molecular Biology II, \\ Faculty of Pharmacy, Complutense University of Madrid, Ciudad Universitaria, Madrid, Spain, ${ }^{4}$ Faculty of Health, Camilo José \\ Cela University, Madrid, Spain, ${ }^{5}$ Neuropsychopharmacology Unit, "Hospital 12 de Octubre" Research Institute, Madrid, \\ Spain, ${ }^{6}$ Laboratory of Medicinal Chemistry, Institute of General Organic Chemistry (CSIC), Madrid, Spain, ${ }^{7}$ Neurovascular \\ Research Group, Instituto de Biomedicina de Sevilla, Hospital Virgen del Rocío, Sevilla, Spain, ${ }^{8}$ Department of Investigation, \\ IRYCIS, Hospital Ramón y Cajal, Madrid, Spain
}

Stroke is a disease of aging affecting millions of people worldwide, and recombinant tissue-type plasminogen activator ( $r$-tPA) is the only treatment approved. However, r-tPA has a low therapeutic window and secondary effects which limit its beneficial outcome, urging thus the search for new more efficient therapies. Among them, neuroprotection based on melatonin or nitrones, as free radical traps, have arisen as drug candidates due to their strong antioxidant power. In this Perspective article, an update on the specific results of the melatonin and several new nitrones are presented.

OPEN ACCESS

Edited by:

Philip P. Foster,

University of Texas Health Science Center at Houston, USA

Reviewed by:

Daniel Ortuño-Sahagún,

Centro Universitario de Ciencias de la

Salud, Mexico

In Koo Hwang,

Seoul National University,

South Korea

${ }^{*}$ Correspondence:

Alejandro Romero manarome@ucm.es José Marco-Contelles iqoc21@iqog.csic.es

Received: 14 September 2016 Accepted: 10 November 2016 Published: 23 November 2016

Citation: Romero A, Ramos E, Patiño P, Oset-Gasque MJ, López-Muñoz $F$, Marco-Contelles J, Ayuso MI and Alcázar A (2016) Melatonin and Nitrones As Potential Therapeutic Agents for Stroke.

Front. Aging Neurosci. 8:281. doi: 10.3389/fnagi.2016.00281
Keywords: stroke, neuroprotection, oxidative stress, melatonin, nitrones

\section{INTRODUCTION}

Stroke is a disease of aging, affecting an increasing number of people worldwide, and the main cause of disability (Flynn et al., 2008; Mathers et al., 2009). The ischemic cascade begins with the energy failure produced by the obstruction of a blood vessel that produces a massive and prolonged release of glutamate (Rothman and Olney, 1986). Physiopathological events associated with brain ischemia are related to oxidative stress process, $\mathrm{Ca}^{2+}$ dyshomeostasis, mitochondrial dysfunction, pro-inflammatory mediators and/or programmed neuronal cell death. In the ischemic stroke, as the result of the obstruction of a blood vessel, a critical reduction in the cerebral blood flow (less than 25\%) occurred in brain, and neurons need a continued supply of oxygen and glucose. Under deprivation of oxygen and glucose, cell death occurs in two phases: (a) first cell death from anoxia/hypoxia and energy depletion, followed by; and (b) reperfusion that increase oxidative stress and free radical formation, excitotoxicity and nitric oxide (NO) production with ulterior energy failure and delayed death (Hossmann, 1994; Choi, 1996; Lee et al., 1999; Ito et al., 2003).

No effective therapeutic drugs to treat or prevent brain damage in ischemic stroke are currently available. Only recombinant tissue plasminogen activator ( $\mathrm{r}-\mathrm{tPA})$ is used to open a blood vessel, but r-tPA has a very narrow therapeutic window of $3.5 \mathrm{~h}$ (Zivin et al., 1985). Preventing brain damage during the ischemic penumbra, despite that it is a hypoperfused and non-functional tissue, is still a viable tissue adjacent to the infarcted core. Finally, new therapeutic agents are needed to recover tissue functionality before cell death, and to be effective in dealing with several targets, including excitotoxicity and disturbed calcium ion homeostasis, mitochondrial failure, oxidative and nitrosative stress, inflammation and apoptosis (Paschen, 2000; Chan, 2001; Iadecola and Alexander, 2001; Lo E. H. et al., 2005; Niizuma et al., 2010). In this Perspective article, we will focus on melatonin and nitrones, well-known radical scavenging and antioxidant agents, for the potential therapy of stroke (Hardeland, 2009). 


\section{MELATONIN}

Stroke as a main cause of brain disease arouses great interest in therapeutic strategies development. The fact that no effective treatment for stroke has yet been approved to date makes melatonin a promising molecule for stroke treatment, either alone or in combination with other agents. A great number of studies had been developed with melatonin prevention or counteracting stroke damage at several steps of the ischemic cascade, such as neuroinflammation, oxidative stress, excitotoxicity and/or apoptosis (Barlow-Walden et al., 1995; Sinha et al., 2001; Rodriguez et al., 2004; Ozacmak et al., 2009; Reiter et al., 2009; Koh, 2012a; Kim and Lee, 2014; Manchester et al., 2015; Zhao et al., 2015; Alluri et al., 2016). We have recently demonstrated that in rat hippocampal slices subjected to oxygen-glucose-deprivation (OGD) and glutamate excitotoxicity, melatonin is able to mediate neuroprotection (Patiño et al., 2016). Previously, we also demonstrated that melatonin exerts its protective effect post-ischemia through the nicotinic acetylcholine receptor $\alpha 7$ subunit modulated by an overexpression of heme oxygenase-1 (Parada et al., 2014).

Numerous experimental in vivo studies evidenced that doses in a range of 5-15 $\mathrm{mg} / \mathrm{kg}$ of melatonin, mainly administered intraperitoneally, exert neuroprotective effects in the ischemic cascade at several critical points (Guerrero et al., 1997; Pei et al., 2003; Pei and Cheung, 2004; Chen H. Y. et al., 2006; Carloni et al., 2008; Signorini et al., 2009; Balduini et al., 2012; AlonsoAlconada et al., 2013; Paredes et al., 2015).

In vivo data confirm the efficacy of this indoleamine. Melatonin has been related to brain repair by comparing pinealectomized and non-pinealectomized animals, observing a greater neurodegeneration in the last group (Manev et al., 1996). Some studies showed its capacity to counteract oxidative stress downregulation or scavenging oxygen and nitrogen species and its free radical detoxification capacity (Guerrero et al., 1997; Pei et al., 2003; Rodriguez et al., 2004; Chen H. Y. et al., 2006; Koh, 2008d).

Other results in stroke models reveal the efficacy of the antiapoptotic properties of melatonin through several mechanisms like increasing levels of Bcl-2, blocking caspase cascade or by preventing mitochondrial depolarization (Sun et al., 2002; Andrabi et al., 2004; Koh, 2008b).

In stroke, elevated extracellular glutamate is critical in neuronal damage. Herein, melatonin has also demonstrated a neuroprotective effect in vivo, mitigating $\mathrm{Ca}^{2+}$ influx (CamelloAlmaraz et al., 2008) via melatonin receptor (Das et al., 2010) by reducing lipid peroxidation (Kim and Kwon, 1999; Wakatsuki et al., 2001). Interestingly, melatonin is a free radical scavenger, which inhibits NO synthesis, a mediator of glutamate and therefore reducing the excitotoxicity (Chung and Han, 2003). In animal stroke models, inflammation leads to numerous pathological events, but melatonin treatment reduces macrophage brain infiltration, activated microglia prevents IL-1 $\beta$, TNF- $\alpha$ and GFAP overexpression (Lee et al., 2007; Paredes et al., 2015), which taken together inhibit the inflammatory response.
Nonetheless, blood brain barrier (BBB) integrity is compromised after cerebrovascular insults, by an increased release of proinflammatory mediators (COX-2, TNF- $\alpha$, IL-1 $\beta$, IL-6), ROS, protein extravasation and interstitial edema. In animal models, melatonin significantly reduces $\mathrm{BBB}$ dysfunction through several mechanisms, NO, ROS and RNS levels, preserves tight junction proteins as claudin- 5 and modulates hyperpermeability (Chen H. Y. et al., 2006; Grossetete et al., 2009; Song et al., 2014; Moretti et al., 2015; Alluri et al., 2016). In light of these results melatonin shows a suitable profile to preserve BBB functional integrity.

Among brain cell populations, neural stem cells (NSCs) have the potential to regenerate new neuronal population. It has been described that after a melatonin treatment, neurogenesis is induced through melatonin receptor MT2 (Chern et al., 2012). Despite molecular neuroprotective mechanisms are not well defined, melatonin has demonstrated to enhance neurogenic cells of the ischemic brain, in striatum neurons and the hippocampal region (Kilic et al., 2008; Ayao et al., 2010; Lee et al., 2014). Furthermore, mesenchymal stem cells (MSCs) are used in implantations after the ischemic insult, but unfortunately this procedure involves the difficulty that approximately the $80 \%$ of the grafted cells do not survive (Roh et al., 2008). Melatonin pre-administration achieves a higher percentage of MSCs survival, also through a receptor-mediated mechanism (Tang et al., 2014).

As far as signal transduction pathways are involved in stroke, melatonin has emerged as a versatile neuroprotective regulator. Melatonin neuroprotective effects are achieved through receptormediated mechanisms (MT1, MT2 and MT3; Reiter et al., 2007; Tan et al., 2007; Slominski et al., 2012; Lacoste et al., 2015). Activation of MT1 melatonin receptor leads to the stimulation of a large variety of $G$ proteins (Brydon et al., 1999), upregulation of MT2 promoted neurogenesis and preservation of BBB integrity (Chern et al., 2012) and stimulation of MT3 may contribute to the antioxidant potential of melatonin (Tan et al., 2007).

In addition, melatonin is highly effective in preventing $\mathrm{Ca}^{2+}$ dyshomeostasis during ischemic brain injury (CamelloAlmaraz et al., 2008; Koh, 2012b). The antiapoptotic effect of melatonin in brain ischemia models is related to its actions at the mitochondria level, preventing the injury-induced reduction of pBad levels and the mitochondrial depolarization inhibiting the mitochondrial permeability transition pore (mPTP; Andrabi et al., 2004; Kilic et al., 2004b; Koh, 2008b). Cell proliferation, differentiation, survival and apoptosis are regulated by the PI3K/Akt signaling pathway and activation of iNOS signaling is associated with PI3K/Akt inhibition. It has been reported that melatonin upregulates this pathway, and decreases iNOS levels (Kilic et al., 2005; Koh, 2008c,d). Matrix metalloproteinases (MMPs) are a family of calcium-dependent zinc-binding proteolytic enzymes that degrade the extracellular matrix (ECM) components of the basement membrane (Montaner et al., 2001). Administration of exogenous melatonin attenuated postischemic MMP-9 activation reducing brain damage in stroke models (Hung et al., 2008). The mitogen-activated protein (MAP) kinase/extracellular-regulated kinase (ERK) 1/2 signaling pathway regulates cell differentiation, growth, survival and 
apoptosis (Pearson et al., 2001). It has been reported that melatonin plays neuroprotection through Akt and ERK1/2 phosphorylation, and activates MEK/ERK/p90RSK/Bad cascade signaling (Kilic et al., 2005; Koh, 2008a). After hypoxic/ischemic brain injury, endogenous vasoconstrictor endothelin-1 (ET-1) levels are elevated leading to exacerbated brain injury, but when melatonin is administered in mice stroke models a beneficial neuroprotective effect was observed inhibiting ET-1 (Kilic et al., 2004a; Lo A. C. et al., 2005). Phosphorylation/dephosphorylation processes are the major form of cellular signaling (Gong and Iqbal, 2008), and their deregulation turns in severe pathologies including neurodegeneration (Sontag et al., 2004), cancer (Ruediger et al., 2001), cardiovascular (Ling et al., 2012) and metabolic disorders (Mandavia and Sowers, 2012). The phosphoprotein phosphatase 2A (PP2A) is the principal member of the family of Ser/Thr phosphatases (Liu et al., 2005), which removes phosphate from serine and threonine residues. Several compounds may activate or protect $\mathrm{PP} 2 \mathrm{~A}$ enzyme activity and have neuroprotective actions in in vivo and in vitro models of brain damage (Shah et al., 2015). In this context, melatonin exerts an upregulation of PP2A enzyme activity, which implies that the PP2A malfunction observed in excitotoxic environments could be mitigated by the administration of melatonin (Koh, 2012a). The protective effect of Silent information regulator 1 (SIRT1) on the brain has been well demonstrated (Yang et al., 2013). Melatonin preserves SIRT1 expression, activates SIRT1 signaling in neuronal cells after hypoxia-ischemia attenuating mitochondrial oxidative damage (Carloni et al., 2014; Yang et al., 2015).

Finally, melatonin has been combined with other drugs, such as t-PA (Chen T. Y. et al., 2006), topiramate (Ozyener et al., 2012), nimodipine and other $\mathrm{Ca}^{2+}$ antagonists (Gelmers et al., 1988; Toklu et al., 2009), meloxicam (Gupta et al., 2002) for stroke therapy, giving promising results.

\section{NITRONES}

Based on the understanding of the biochemical processes involved in the formation and development of a stroke, number of products have been developed targeting the different ischemic and reperfusion events. Despite the promising initial results, neuroprotection drugs for stroke have failed in advanced clinical phases, and consequently, no neuroprotective agent has been approved by the FDA for stroke therapy. However, neuroprotection is still a choice, and oxidative stress, a suitable biological target. In this context, antioxidants such as $N$-t-butylphenylnitrone (PBN; Figure 1; Novelli et al., 1986) and NXY-059 (Figure 1; Dehouck et al., 2002), have attracted the interest of a number of laboratories, resulting in therapeutic candidates for cancer (Inoue et al., 2007; Floyd et al., 2008, 2010, 2011; Costa et al., 2015), neurodegenerative disorders (Floyd et al., 2000), hearing loss (Floyd et al., 2008) and stroke (Doggrell, 2006; Floyd et al., 2008). NXY-059 (Figure 1) (Kuroda et al., 1999) is a well-known free radical scavenger with good neuroprotective profile in rat models of transient and permanent focal ischemia, and stroke model in rodents,<smiles></smiles><smiles>CC(C)(C)N=[N+]([O-])Cc1ccc(S(=O)(=O)O[Na])cc1S(=O)(=O)O[Na]</smiles><smiles>Cc1ccc2nc(Cl)c(/C=[N+](\[O-])Cc3ccccc3)cc2c1</smiles>
RP19

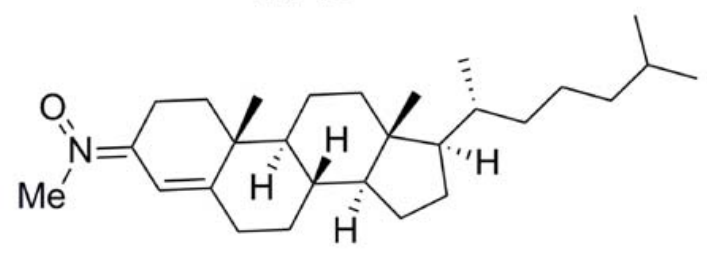

F2

FIGURE 1 | Structures of nitrones $\mathrm{N}$-t-butylphenylnitrone (PBN), NXY-059, and the nitrones RP19 and F2, assesed in our laboratories.

which has been launched several times in different program in advanced clinical studies, although with limited success (Macleod et al., 2008). In fact and in addition, tert-butylnitrones, such as NXY-059, are known to afford $t$-butylhydroxylamines as powerful radical scavengers, after hydrolysis, that further could be oxidized to 2-methyl-2-nitrosopropane which then may synthesize NO radical, the source and origin of the neuroprotection, as it has been already reported for NO donors (Godínez-Rubí et al., 2013). Recently reported new developments have highlighted the not previously described and powerful neuroprotective effect shown by new PBN derivatives bearing $N$-aryl substituents on human neuroblastoma cells, under induced in vitro experimental oxidative stress (Matias et al., 2016).

Starting in 2008, the group led by Marco-Contelles (CSIC, Madrid, Spain) has designed, synthesized and developed a number of nitrones for the potential treatment of stroke, the most interesting compounds being RP19 (Figure 1;

TABLE 1A | In vitro antioxidant activity (A) and neuroprotection in neuronal cultures and in vivo model of ischemia (B).

\begin{tabular}{|c|c|c|c|c|}
\hline Nitrone & AAPH $(\%)^{a}(\min )^{b}$ & DPPH $(\%)^{c}$ &.$O H(\%)^{d}$ & $\mathrm{O}_{2} \cdot{ }^{-}(\%)^{\mathrm{e}}$ \\
\hline RP19g & 37 (78) & 42.3 & 95 & 23 \\
\hline$F 2^{h}$ & $55(\mathrm{nd})^{f}$ & 4 & 83 & $(n d)^{f}$ \\
\hline PBN & no $(0)$ & $(n d)^{f}$ & 90 & 15 \\
\hline
\end{tabular}

a Determined at $0.1 \mathrm{mM}$; ${ }^{b}$ Induction time $\left(t_{i n h}\right)$ produced by the tested nitrones; ${ }^{c}$ Determined at $0.5 \mathrm{mM}$ except for F2, that was determined at $0.1 \mathrm{mM}$; ${ }^{d}$ Determined at $0.1 \mathrm{mM}$; ${ }^{e}$ Determined at $0.1 \mathrm{mM}$; ${ }^{f}$ nd: not determined; ${ }^{g}$ Chioua

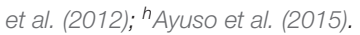


TABLE 1B | In vitro antioxidant activity (A) and neuroprotection in neuronal cultures and in vivo model of ischemia (B).

\begin{tabular}{|c|c|c|c|c|c|c|}
\hline Nitrone & Cc & Neuroprotection (\%) & Time after reperfusion & Cc & Cell death reduction (\%) & Apoptosis reduction (\%) \\
\hline PBN & $5 \mathrm{mM}$ & $13.4 \pm 1.9$ & & & & \\
\hline NXY-059 & $250 \mu \mathrm{M}$ & $56.8 \pm 2.5$ & $5 d$ & $40 \mathrm{mg} / \mathrm{kg}$ & $17(\mathrm{CA} 1) 70(\mathrm{C})$ & 21 (CA1) 55 (C) \\
\hline \multirow[t]{2}{*}{ RP19a } & $10 \mu \mathrm{M}$ & $70.9 \pm 2.2$ & $5 d$ & $0.5 \mathrm{mg} / \mathrm{kg}$ & $35(\mathrm{CA} 1)^{* * *} 63(\mathrm{C})^{*}$ & $38(\mathrm{CA} 1)^{* *} 79(\mathrm{C})^{*}$ \\
\hline & $50 \mu \mathrm{M}$ & $87.5 \pm 3.2$ & & & & \\
\hline \multirow[t]{2}{*}{$\mathrm{F} 2^{\mathrm{b}}$} & $1 \mu \mathrm{M}$ & $54.3 \pm 1.3$ & $5 d$ & $0.05 \mathrm{mg} / \mathrm{kg}$ & 20 (CA1) 66 (C) & $30(\mathrm{CA} 1)^{*} 89(\mathrm{C})^{*}$ \\
\hline & $5 \mu \mathrm{M}$ & $80.7 \pm 2.7$ & $5 d$ & $0.1 \mathrm{mg} / \mathrm{kg}$ & $27(\mathrm{CA} 1)^{* *} 83(\mathrm{C})^{*}$ & $35(\mathrm{CA} 1)^{* *} 91(\mathrm{C})^{*}$ \\
\hline
\end{tabular}

${ }^{*} P<0.05,{ }^{* *} P<0.01$ and ${ }^{* * *} P<0.001$, compared with vehicle by Dunnett's post test after ANOVA. ${ }^{a}$ Chioua et al. (2012). ${ }^{b}$ Ayuso et al. (2015).

Chioua et al., 2012), and F2 (Ayuso et al., 2015; Figure 1), in collaboration with Dr. Dimitra J. Hadjipavlou-Litina (Aristotle University of Thessaloniki, Greece) and Dr. Alcázar (Hospital Ramón y Cajal, Madrid, Spain).

As radical-trapping agents, nitrones are expected to delay or prevent oxidation of easily oxidizable substrates, therefore being considered antioxidants. In vitro radical trapping and antioxidant activity were studied for nitrones RP19 and F2, and PBN as reference compound, using the DPPH quenching, $\bullet \mathrm{OH}$ and $\mathrm{O}_{2}{ }^{\cdot-}$ scavenging, and inhibition of lipid peroxidation by AAPH tests. As shown in Table 1A, DPPH and $\mathrm{O}_{2}{ }^{-}-$scavenging activities were low in general, with moderate values for RP19 (42.3\% and $23 \%)$. Scavenging of $\bullet \mathrm{OH}$, as one of the most toxic radicals generated during ischemic stress, was also determined, showing that higher trapping activities were achieved than reference compound PBN.

Testing in neuronal cultures and in in vivo experiments were next evaluated. Thus, the neuroprotective effect of nitrones RP19, F2, as well as PBN and NXY-059 as standards were studied in primary neuronal cultures, which were subjected to OGD as an in vitro model of ischemia. Cell viability was evaluated by quantification of living, metabolically active cells, as determined by the MTT assay. Neuroprotection is expressed as the percentage to reach the control value (100\%), from the untreated ischemic neurons value $(0 \%)$ (Table 1B). As shown, all the nitrones tested afforded values in all cases higher than the one determined for PBN (13.4 $\pm 1.9 \%$ at $5 \mathrm{mM})$ and NXY-059 (56.8 $\pm 2.5 \%$ at $250 \mu \mathrm{M})$, being remarkable for those observed for nitrones RP19 $(87.5 \pm 3.2 \%$ at $50 \mu \mathrm{M})$ and F2 $(80.7 \pm 2.7 \%$ at $5 \mu \mathrm{M})$. Next, transient global brain ischemia was performed on adult rats by the standard fourvessel occlusion model, in which carotid arteries are occluded during $15 \mathrm{~min}$ and $24 \mathrm{~h}$ after the irreversible occlusion of both vertebral arteries by electrocoagulation (Pulsinelli and Brierley, 1979; García-Bonilla et al., 2007). Ischemic animals were treated with RP19 and F2; NXY-059 diluted in 10\% ethanol in saline as a vehicle by intraperitoneal injection when carotid arteries were un-clamped for reperfusion. Animals were studied after 5 days of reperfusion (R5d) after killing by transcardiac perfusion performed under deep anesthesia. Treatments were blindly and randomly performed and body temperature of $37^{\circ} \mathrm{C}$ was maintained (Table 1B). Cell death and apoptosis were assessed in the hippocampal cornu ammonis 1 (CA1) region and cerebral cortex (C). Nitrones RP19 and F2 showed higher inhibition of cell death than for NXY-059. In particular, best results were obtained with $\mathrm{F} 2$ at $0.1 \mathrm{mg} / \mathrm{Kg}$ concentration, and RP19 at $0.5 \mathrm{mg} / \mathrm{Kg}$ concentration. Apoptosis reduction by F2 (35\% in hippocampal
CA1, 91\% in cortex, at $0.1 \mathrm{mg} / \mathrm{kg}$ concentration) and RP19 (38\% in hippocampal CA1, 79\% in cortex, at $0.5 \mathrm{mg} / \mathrm{kg}$ concentration) showed the best results, both higher than the values observed for NXY-059 (21\% in hippocampal CA1, 55\% in cortex), at the same concentration.

\section{CONCLUDING REMARKS}

In this Perspective article, we have updated the current neuroprotection studies and results for the development of melatonin and new nitrones for stroke. Regarding melatonin, the favorable in vitro and in vivo results reported, together with its great safety profile even at high concentrations, convert this indoleamine into an extraordinary therapeutic option to reduce the multiplicity of effects resulting from the brain ischemic cascade. Unfortunately, there is a lack of clinical studies with melatonin that confirm these results, maybe due to the lack of patentability of this molecule. The most recent results reported by Marco-Contelles' group confirm that the neuroprotective strategy based on quinolylnitrones and cholesteronitrones have created great expectations that must still re-confirmed. These nitrones appear as promising agents due to robust antioxidant properties capable to target distinct steps of the biochemical pathways during and after the ischemic insult. Nonetheless, due to the preclinical results reviewed above, the use of melatonin or the new nitrones shown here, or better, multifunctional nitrones bearing the melatonin pharmacophoric motif, may rise as a potential tool to fight against brain ischemia injury and its multiple pathophysiological side-effects.

\section{AUTHOR CONTRIBUTIONS}

AR and JM-C conceived the present "Perspective". AR wrote the "melatonin" part, and JM-C wrote the "nitrone" section. MA and AA obtained the unpublished results shown in Table 1B corresponding to the global ischemia experiment of nitrone RP19. MJO-G and FL-M critically read and corrected the manuscript. AR, JM-C, MJO-G and FL-M approved the manuscript.

\section{ACKNOWLEDGMENTS}

JM-C is indebted to Ministerio de Economía y Competitividad (es) (MINECO) for grants SAF2012-33304, and SAF2015-65586-R. FL-M, MJO-G and JM-C thank Universidad Camilo José Cela (Project 2015-12 (NITROSTROKE)) for continued support. 


\section{REFERENCES}

Alluri, H., Wilson, R. L., Anasooya Shaji, C., Wiggins-Dohlvik, K., Patel, S., Liu, Y., et al. (2016). Melatonin preserves blood-brain barrier integrity and permeability via matrix metalloproteinase-9 inhibition. PLoS One 11:e0154427. doi: 10.1371/journal.pone. 0154427

Alonso-Alconada, D., Alvarez, A., Arteaga, O., Martínez-Ibargüen, A., and Hilario, E. (2013). Neuroprotective effect of melatonin: a novel therapy against perinatal hypoxia-ischemia. Int. J. Mol. Sci. 14, 9379-9395. doi: 10. 3390/ijms14059379

Andrabi, S. A., Sayeed, I., Siemen, D., Wolf, G., and Horn, T. F. (2004). Direct inhibition of the mitochondrial permeability transition pore: a possible mechanism responsible for anti-apoptotic effects of melatonin. FASEB J. 18, 869-871. doi: 10.1096/fj.03-1031fje

Ayao, M. S., Olaleyer, O., and Ihunwo, A. O. (2010). Melatonin potentiates cells proliferation in the dentate gyrus following ischemic brain injury in adult rats. J. Animal. Vet Adv. 9, 1633-1638. doi: 10.3923/javaa.2010.16 33.1638

Ayuso, M. I., Chioua, M., Martínez-Alonso, E., Soriano, E., Montaner, J., Masjuán, J., et al. (2015). CholesteroNitrones for stroke. J. Med. Chem. 58, 6704-6709. doi: 10.1021/acs.jmedchem.5b00755

Balduini, W., Carloni, S., Perrone, S., Bertrando, S., Tataranno, M. L., Negro, S., et al. (2012). The use of melatonin in hypoxic-ischemic brain damage: an experimental study. J. Matern. Fetal Neonatal Med. 25, 119-124. doi: 10. 3109/14767058.2012.663232

Barlow-Walden, L. R., Reiter, R. J., Abe, M., Pablos, M., Menendez-Pelaez, A., Chen, L. D., et al. (1995). Melatonin stimulates brain glutathione peroxidase activity. Neurochem. Int. 26, 497-502. doi: 10.1016/0197-0186(94)00154-m

Brydon, L., Roka, F., Petit, L., de Coppet, P., Tissot, M., Barrett, P., et al. (1999). Dual signaling of human Mella melatonin receptors via $\mathrm{G}_{\mathrm{i} 2}, \mathrm{G}_{\mathrm{i} 3}$ and $\mathrm{G}_{\mathrm{q} / 11}$ proteins. Mol. Endocrinol. 13, 2025-2038. doi: 10.1210/me.13. 12.2025

Camello-Almaraz, C., Gomez-Pinilla, P. J., Pozo, M. J., and Camello, P. J. (2008). Age-related alterations in $\mathrm{Ca}^{2+}$ signals and mitochondrial membrane potential in exocrine cells are prevented by melatonin. J. Pineal Res. 45, 191-198. doi: 10. 1111/j.1600-079x.2008.00576.x

Carloni, S., Albertini, M. C., Galluzzi, L., Buonocore, G., Proietti, F., and Balduini, W. (2014). Melatonin reduces endoplasmic reticulum stress and preserves sirtuin 1 expression in neuronal cells of newborn rats after hypoxiaischemia. J. Pineal Res. 57, 192-199. doi: 10.1111/jpi.12156

Carloni, S., Perrone, S., Buonocore, G., Longini, M., Proietti, F., and Balduini, W. (2008). Melatonin protects from the long-term consequences of a neonatal hypoxic-ischemic brain injury in rats. J. Pineal Res. 44, 157-164. doi: 10.1111/j. 1600-079x.2007.00503.x

Chan, P. H. (2001). Reactive oxygen radicals in signaling and damage in the ischemic brain. J. Cereb. Blood Flow Metab. 21, 2-14. doi: 10.1097/00004647200101000-00002

Chen, H. Y., Chen, T. Y., Lee, M. Y., Chen, S. T., Hsu, Y. S., Kuo, Y. L., et al. (2006). Melatonin decreases neurovascular oxidative/nitrosative damage and protects against early increases in the blood-brain barrier permeability after transient focal cerebral ischemia in mice. J. Pineal Res. 41, 175-182. doi: 10.1111/j.1600079x.2006.00351.x

Chen, T. Y., Lee, M. Y., Chen, H. Y., Kuo, Y. L., Lin, S. C., Wu, T. S., et al. (2006). Melatonin attenuates the postischemic increase in blood-brain barrier permeability and decreases hemorrhagic transformation of tissue-plasminogen activator therapy following ischemic stroke in mice. J. Pineal Res. 40, 242-250. doi: 10.1111/j.1600-079x.2005.00307.x

Chern, C. M., Liao, J. F., Wang, Y. H., and Shen, Y. C. (2012). Melatonin ameliorates neural function by promoting endogenous neurogenesis through the MT2 melatonin receptor in ischemic-stroke mice. Free Radic. Biol. Med. 52, 1634-1647. doi: 10.1016/j.freeradbiomed.2012.01.030

Chioua, M., Sucunza, D., Soriano, E., Hadjipavlou-Litina, D., Alcázar, A., Ayuso, I., et al. (2012). $\alpha$-aryl-N-alkyl nitrones, as potential agents for stroke treatment: synthesis, theoretical calculations, antioxidant, anti-inflammatory, neuroprotective and brain-blood barrier permeability properties. J. Med. Chem. 55, 153-168. doi: 10.1021/jm201105a

Choi, D. W. (1996). Ischemia-induced neuronal apoptosis. Curr. Opin. Neurobiol. 6, 667-672. doi: 10.1016/s0959-4388(96)80101-2
Chung, S. Y., and Han, S. H. (2003). Melatonin attenuates kainic acid-induced hippocampal neurodegeneration and oxidative stress through microglial inhibition. J. Pineal Res. 34, 95-102. doi: 10.1034/j.1600-079x.2003.00010.x

Costa, D. S., Martino, T., Magalhaes, F. C., Justo, G., Coelho, M. G., Barcellos, J. C., et al. (2015). Synthesis of N-methylarylnitrones derived from alkyloxybenzaldehydes and antineoplastic effect on human cancer cell lines. Bioorg. Med. Chem. 23, 2053-2061. doi: 10.1016/j.bmc.2015.03.014

Das, A., McDowell, M., Pava, M. J., Smith, J. A., Reiter, R. J., Woodward, J. J., et al. (2010). The inhibition of apoptosis by melatonin in VSC4.1 motoneurons exposed to oxidative stress, glutamate excitotoxicity, or TNF- $\alpha$ toxicity involves membrane melatonin receptors. J. Pineal Res. 48, 157-169. doi: 10.1111/j.1600079x.2009.00739.x

Dehouck, M. P., Cecchelli, R., Richard Green, A., Renftel, M., and Lundquist, S. (2002). In vitro blood-brain barrier permeability and cerebral endothelial cell uptake of the neuroprotective nitrone compound NXY-059 in normoxic, hypoxic and ischemic conditions. Brain Res. 955, 229-235. doi: 10.1016/s00068993(02)03469-8

Doggrell, S. A. (2006). Nitrone spin on cerebral ischemia. Curr. Opin. Investig. Drugs 7, 20-24.

Floyd, R. A., Chandru, H. K., He, T., and Towner, R. (2011). Anti-cancer activity of nitrones and observations on mechanism of action. Anticancer Agents Med. Chem. 11, 373-379. doi: 10.2174/187152011795677517

Floyd, R. A., Hensley, K., and Bing, G. (2000). Evidence for enhanced neuroinflammatory processes in neurodegenerative diseases and the action of nitrones as potential therapeutics. J. Neural Transm. Suppl. 60, 387-414. doi: 10. 1007/978-3-7091-6301-6_28

Floyd, R. A., Kopke, R. D., Choi, C. H., Foster, S. B., Doblas, S., and Towner, R. A. (2008). Nitrones as therapeutics. Free Radic. Biol. Med. 45, 1361-1374. doi: 10. 1016/j.freeradbiomed.2008.08.017

Floyd, R. A., Towner, R. A., Wu, D., Abbott, A., Cranford, R., Branch, D., et al. (2010). Anti-cancer activity of nitrones in the $\mathrm{Apc}(\mathrm{Min} /+)$ model of colorectal cancer. Free Radic. Res. 44, 108-117. doi: 10.3109/10715760903321796

Flynn, R. W., MacWalter, R. S., and Doney, A. S. (2008). The cost of cerebral ischaemia. Neuropharmacology 55, 250-256. doi: 10.1016/j.neuropharm.2008. 05.031

García-Bonilla, L., Cid, C., Alcázar, A., Burda, J., Ayuso, I., and Salinas, M. (2007). Regulatory proteins of eukaryotic initiation factor $2-\alpha$ subunit (eIF2 $\alpha$ ) phosphatase, under ischemic reperfusion and tolerance. J. Neurochem. 103, 1368-1380. doi: 10.1111/j.1471-4159.2007.04844.x

Gelmers, H. J., Gorter, K., de Weerdt, C. J., and Wiezer, H. J. (1988). A controlled trial of nimodipine in acute ischemic stroke. N. Engl. J. Med. 318, 203-207. doi: 10.1056/nejm198801283180402

Godínez-Rubí, M., Rojas-Mayorquín, A. E., and Ortuño-Sahagún, D. (2013). Nitric oxide donors as neuroprotective agents after an ischemic strokerelated inflammatory reaction. Oxid. Med. Cell. Longev. 2013:297357. doi: 10. $1155 / 2013 / 297357$

Gong, C. X., and Iqbal, K. (2008). Hyperphosphorylation of microtubuleassociated protein tau: a promising therapeutic target for Alzheimer disease Curr. Med. Chem. 15, 2321-2328. doi: 10.2174/092986708785909111

Grossetete, M., Phelps, J., Arko, L., Yonas, H., and Rosenberg, G. A. (2009). Elevation of matrix metalloproteinases 3 and 9 in cerebrospinal fluid and blood in patients with severe traumatic brain injury. Neurosurgery $65,702-708$. doi: 10.1227/01.NEU.0000351768.11363.48

Guerrero, J. M., Reiter, R. J., Ortiz, G. G., Pablos, M. I., Sewerynek, E., and Chuang, J. I. (1997). Melatonin prevents increases in neural nitric oxide and cyclic GMP production after transient brain ischemia and reperfusion in the Mongolian gerbil (Meriones unguiculatus). J. Pineal Res. 23, 24-31. doi: 10. 1111/j.1600-079x.1997.tb00331.x

Gupta, Y. K., Chaudhary, G., and Sinha, K. (2002). Enhanced protection by melatonin and meloxicam combination in a middle cerebral artery occlusion model of acute ischemic stroke in rat. Can. J. Physiol. Pharmacol. 80, 210-217. doi: $10.1139 / \mathrm{y} 02-052$

Hardeland, H. (2009). Neuroprotection by radical avoidance: search for suitable agents. Molecules 14, 5054-5102. doi: 10.3390/molecules 14125054

Hossmann, K. A. (1994). Viability thresholds and the penumbra of focal ischemia. Ann. Neurol. 36, 557-565. doi: 10.1002/ana.410360404

Hung, Y. C., Chen, T. Y., Lee, E. J., Chen, W. L., Huang, S. Y., Lee, W. T., et al. (2008). Melatonin decreases matrix metalloproteinase- 9 activation and 
expression and attenuates reperfusion-induced hemorrhage following transient focal cerebral ischemia in rats. J. Pineal Res. 45, 459-467. doi: 10.1111/j.1600079x.2008.00617.x

Iadecola, C., and Alexander, M. (2001). Cerebral ischemia and inflammation. Curr. Opin. Neurol. 14, 89-94. doi: 10.1097/00019052-20010200000014

Inoue, Y., Asanuma, T., Smith, N., Saunders, D., Oblander, J., Kotake, Y., et al. (2007). Modulation of Fas-FasL related apoptosis by PBN in the early phases of choline deficient diet-mediated hepatocarcinogenesis in rats. Free Radic. Res. 41, 972-980. doi: 10.1080/10715760701447322

Ito, H., Kanno, I., Ibaraki, M., Hatazawa, J., and Miura, S. (2003). Changes in human cerebral blood flow and cerebral blood volume during hypercapnia and hypocapnia measured by positron emission tomography. J. Cereb. Blood Flow Metab. 23, 665-670. doi: 10.1097/01.wcb.0000067721.64998.f5

Kilic, E., Kilic, U., Bacigaluppi, M., Guo, Z., Abdallah, N. B., Wolfer, D. P., et al. (2008). Delayed melatonin administration promotes neuronal survival, neurogenesis and motor recovery and attenuates hyperactivity and anxiety after mild focal cerebral ischemia in mice. J. Pineal Res. 45, 142-148. doi: 10.1111/j. 1600-079x.2008.00568.x

Kilic, E., Kilic, U., Reiter, R. J., Bassetti, C. L., and Hermann, D. M. (2004a). Prophylactic use of melatonin protects against focal cerebral ischemia in mice: role of endothelin converting enzyme-1. J. Pineal Res. 37, 247-251. doi: 10. 1111/j.1600-079x.2004.00162.x

Kilic, E., Kilic, U., Yulug, B., Hermann, D. M., and Reiter, R. J. (2004b). Melatonin reduces disseminate neuronal death after mild focal ischemia in mice via inhibition of caspase- 3 and is suitable as an add-on treatment to tissueplasminogen activator. J. Pineal Res. 36, 171-176. doi: 10.1046/j.1600-079x. 2003.00115.x

Kilic, U., Kilic, E., Reiter, R. J., Bassetti, C. L., and Hermann, D. M. (2005). Signal transduction pathways involved in melatonin-induced neuroprotection after focal cerebral ischemia in mice. J. Pineal Res. 38, 67-71. doi: 10.1111/j.1600079x.2004.00178.x

Kim, H. J., and Kwon, J. S. (1999). Effects of placing micro-implants of melatonin in striatum on oxidative stress and neuronal damage mediated by N-methylD-aspartate (NMDA) and non-NMDA receptors. Arch. Pharm. Res. 22, 35-43. doi: $10.1007 /$ bf02976433

Kim, S. J., and Lee, S. R. (2014). Protective effect of melatonin against transient global cerebral ischemia-induced neuronal cell damage via inhibition of matrix metalloproteinase-9. Life Sci. 94, 8-16. doi: 10.1016/j.lfs.2013.11.013

Koh, P. O. (2008a). Melatonin attenuates the cerebral ischemic injury via the MEK/ERK/p90RSK/bad signaling cascade. J. Vet. Med. Sci. 70, 1219-1223. doi: $10.1292 /$ jvms.70.1219

Koh, P. O. (2008b). Melatonin attenuates the focal cerebral ischemic injury by inhibiting the dissociation of pBad from 14-3-3. J. Pineal Res. 44, 101-106. doi: 10.1111/j.1600-079x.2007.00495.x

Koh, P. O. (2008c). Melatonin prevents the injury-induced decline of Akt/forkhead transcription factors phosphorylation. J. Pineal Res. 45, 199-203. doi: 10.1111/j. 1600-079x.2008.00577.x

Koh, P. O. (2008d). Melatonin regulates nitric oxide synthase expression in ischemic brain injury. J. Vet. Med. Sci. 70, 747-750. doi: 10.1292/jvms.70.747

Koh, P. O. (2012a). Melatonin attenuates decrease of protein phosphatase $2 \mathrm{~A}$ subunit B in ischemic brain injury. J. Pineal Res. 52, 57-61. doi: 10.1111/j.1600079x.2011.00918.x

Koh, P. O. (2012b). Melatonin regulates the calcium-buffering proteins, parvalbumin and hippocalcin, in ischemic brain injury. J. Pineal Res. 53, 358-365. doi: 10.1111/j.1600-079x.2012.01005.x

Kuroda, S., Tsuchidate, R., Smith, M. L., Maples, K. R., and Siesjo, B. K. (1999). Neuroprotective effects of a novel nitrone, NXY-059, after transient focal cerebral ischemia in the rat. J. Cereb. Blood Flow Metab. 19, 778-787. doi: 10. 1097/00004647-199907000-00008

Lacoste, B., Angeloni, D., Dominguez-Lopez, S., Calderoni, S., Mauro, A., Fraschini, F., et al. (2015). Anatomical and cellular localization of melatonin MT1 and MT2 receptors in the adult rat brain. J. Pineal Res. 58, 397-417. doi: $10.1111 /$ jpi.12224

Lee, M. Y., Kuan, Y. H., Chen, H. Y., Chen, T. Y., Chen, S. T., Huang, C. C., et al. (2007). Intravenous administration of melatonin reduces the intracerebral cellular inflammatory response following transient focal cerebral ischemia in rats. J. Pineal Res. 42, 297-309. doi: 10.1111/j.1600-079x.2007.00420.x
Lee, M., Lee, S., and Hong, Y. (2014). Melatonin plus treadmill exercise synergistically promotes neurogenesis and reduce apoptosis in focal cerebral ischemic rats (877.17). FASEB J. 28. Supplement 877.17.

Lee, J. M., Zipfel, G. J., and Choi, D. W. (1999). The changing landscape of ischaemic brain injury mechanisms. Nature 399, A7-A14. doi: 10 1038/399a007

Ling, S., Sun, Q., Li, Y., Zhang, L., Zhang, P., Wang, X., et al. (2012). CKIP1 inhibits cardiac hypertrophy by regulating class II histone deacetylase phosphorylation through recruiting PP2A. Circulation 126, 3028-3040. doi: 10. 1161/CIRCULATIONAHA.112.102780

Liu, F., Grundke-Iqbal, I., Iqbal, K., and Gong, C. X. (2005). Contributions of protein phosphatases PP1, PP2A, PP2B and PP5 to the regulation of tau phosphorylation. Eur. J. Neurosci. 22, 1942-1950. doi: 10.1111/j.1460-9568. 2005.04391.x

Lo, A. C., Chen, A. Y., Hung, V. K., Yaw, L. P., Fung, M. K., Ho, M. C., et al. (2005). Endothelin-1 overexpression leads to further water accumulation and brain edema after middle cerebral artery occlusion via aquaporin 4 expression in astrocytic end-feet. J. Cereb. Blood Flow Metab. 25, 998-1011. doi: 10.1038/sj. jcbfm.9600108

Lo, E. H., Moskowitz, M. A., and Jacobs, T. P. (2005). Exciting, radical, suicidal: how brain cells die after stroke. Stroke 36, 189-192. doi: 10.1161/01.STR. 0000153069.96296.fd

Macleod, M. R., van der Worp, H. B., Sena, E. S., Howells, D. W., Dirnagl, U., and Donnan, G. A. (2008). Evidence for the efficacy of NXY-059 in experimental focal cerebral ischaemia is confounded by study quality. Stroke 39, 2824-2829. doi: 10.1161/STROKEAHA.108.515957

Manchester, L. C., Coto-Montes, A., Boga, J. A., Andersen, L. P., Zhou, Z., Galano, A., et al. (2015). Melatonin: an ancient molecule that makes oxygen metabolically tolerable. J. Pineal Res. 59, 403-419. doi: 10.1111/jpi. 12267

Mandavia, C., and Sowers, J. R. (2012). Phosphoprotein phosphatase PP2A regulation of insulin receptor substrate 1 and insulin metabolic signaling. Cardiorenal Med. 2, 308-313. doi: 10.1159/000343889

Manev, H., Uz, T., Kharlamov, A., and Joo, J. Y. (1996). Increased brain damage after stroke or excitotoxic seizures in melatonin-deficient rats. FASEB J. 10, 1546-1551.

Mathers, C. D., Boerma, T., and Ma Fat, D. (2009). Global and regional causes of death. Br. Med. Bull. 92, 7-32. doi: 10.1093/bmb/ldp028

Matias, A. C., Biazolla, G., Cerchiaro, G., and Keppler, A. T. (2016). $\alpha$-Aryl-Naryl nitrones: synthesis and screening of a new scaffold for cellular protection against an oxidative toxic stimulus. Bioorg. Med. Chem. 24, 232-239. doi: 10. 1016/j.bmc.2015.12.007

Montaner, J., Alvarez-Sabin, J., Molina, C. A., Anglés, A., Abilleira, S., Arenillas, J., et al. (2001). Matrix metalloproteinase expression is related to hemorrhagic transformation after cardioembolic stroke. Stroke 32, 2762-2767. doi: 10. 1161/hs1201.99512

Moretti, R., Zanin, A., Pansiot, J., Spiri, D., Manganozzi, L., Kratzer, I., et al. (2015). Melatonin reduces excitotoxic blood-brain barrier breakdown in neonatal rats. Neuroscience 311, 382-397. doi: 10.1016/j.neuroscience.2015. 10.044

Niizuma, K., Yoshioka, H., Chen, H., Kim, G. S., Jung, J. E., Katsu, M., et al. (2010). Mitochondrial and apoptotic neuronal death signaling pathways in cerebral ischemia. Biochim. Biophys. Acta 1802, 92-99. doi: 10.1016/j.bbadis.2009. 09.002

Novelli, G. P., Angiolini, P., Tani, R., Consales, G., and Bordi, L. (1986). PhenylT-butyl-nitrone is active against traumatic shock in rats. Free Radic. Res. Commun. 1, 321-327. doi: 10.3109/10715768609080971

Ozacmak, V. H., Barut, F., and Ozacmak, H. S. (2009). Melatonin provides neuroprotection by reducing oxidative stress and HSP70 expression during chronic cerebral hypoperfusion in ovariectomized rats. J. Pineal Res. 47, 156-163. doi: 10.1111/j.1600-079x.2009.00695.x

Ozyener, F., Çetinkaya, M., Alkan, T., Gören, B., Kafa, I. M., Kurt, M. A., et al. (2012). Neuroprotective effects of melatonin administered alone or in combination with topiramate in neonatal hypoxic-ischemic rat model. Restor. Neurol. Neurosci. 30, 435-444. doi: 10.3233/RNN-2012120217

Parada, E., Buendia, I., León, R., Negredo, P., Romero, A., Cuadrado, A., et al. (2014). Neuroprotective effect of melatonin against ischemia is partially 
mediated by $\alpha-7$ nicotinic receptor modulation and HO-1 overexpression. J. Pineal Res. 56, 204-212. doi: 10.1111/jpi.12113

Paredes, S. D., Rancan, L., Kireev, R., González, A., Louzao, P., González, P., et al. (2015). Melatonin counteracts at a transcriptional level the inflammatory and apoptotic response secondary to ischemic brain injury induced by middle cerebral artery blockade in aging rats. Biores. Open Access 4, 407-416. doi: 10. 1089/biores.2015.0032

Paschen, W. (2000). Role of calcium in neuronal cell injury: which subcellular compartment is involved? Brain Res. Bull. 53, 409-413. doi: 10.1016/s03619230(00)00369-5

Patiño, P., Parada, E., Farré-Alins, V., Molz, S., Cacabelos, R., MarcoContelles, J., et al. (2016). Melatonin protects against oxygen and glucose deprivation by decreasing extracellular glutamate and Nox-derived ROS in rat hippocampal slices. Neurotoxicology 57, 61-68. doi: 10.1016/j.neuro.2016. 09.002

Pearson, G., Robinson, F., Beers Gibson, T., Xu, B. E., Karandikar, M., Berman, K., et al. (2001). Mitogen-activated protein (MAP) kinase pathways: regulation and physiological functions. Endocr. Rev. 22, 153-183. doi: 10.1210/er. 22.2.153

Pei, Z., and Cheung, R. T. (2004). Pretreatment with melatonin exerts antiinflammatory effects against ischemia/reperfusion injury in a rat middle cerebral artery occlusion stroke model. J. Pineal Res. 37, 85-91. doi: 10.1111/j. 1600-079x.2004.00138.x

Pei, Z., Fung, P. C. W., and Cheung, R. T. F. (2003). Melatonin reduces nitric oxide level during ischemia but not blood-brain barrier breakdown during reperfusion in a rat middle cerebral artery occlusion stroke model. J. Pineal Res. 34, 110-118. doi: 10.1034/j.1600-079x.2003.00014.x

Pulsinelli, W. A., and Brierley, J. B. (1979). A new model of bilateral hemispheric ischemia in the unanesthetized rat. Stroke 10, 267-272. doi: 10.1161/01.str.10. 3.267

Reiter, R. J., Paredes, S. D., Manchester, L. C., and Tan, D. X. (2009). Reducing oxidative/nitrosative stress: a newly-discovered genre for melatonin. Crit. Rev. Biochem. Mol. Biol. 44, 175-200. doi: 10.1080/104092309030 44914

Reiter, R. J., Tan, D. X., Manchester, L. C., Pilar Terron, M., Flores, L. J., and Koppisepi, S. (2007). Medical implications of melatonin: receptor-mediated and receptor-independent actions. Adv. Med. Sci. 52, 11-28.

Rodriguez, C., Mayo, J. C., Sainz, R. M., Antolín, I., Herrera, F., Martín, V., et al. (2004). Regulation of antioxidant enzymes: a significant role for melatonin. J. Pineal Res. 36, 1-9. doi: 10.1046/j.1600-079x.2003.00092.x

Roh, J.-K., Jung, K.-H., and Chu, K. (2008). Adult stem cell transplantation in stroke: its limitations and prospects. Curr. Stem Cell Res. Ther. 3, 185-196. doi: $10.2174 / 157488808785740352$

Rothman, S. M., and Olney, J. W. (1986). Glutamate and the pathophysiology of hypoxic-ischemic brain damage. Ann. Neurol. 19, 105-111. doi: 10.1002/ana. 410190202

Ruediger, R., Pham, H. T., and Walter, G. (2001). Disruption of protein phosphatase $2 \mathrm{~A}$ subunit interaction in human cancers with mutations in the $\mathrm{A} \alpha$ subunit gene. Oncogene 12, 10-15. doi: 10.1038/sj.onc.1204059

Shah, F. A., Park, D. J., Gim, S. A., and Koh, P. O. (2015). Curcumin treatment recovery the decrease of protein phosphatase $2 \mathrm{~A}$ subunit $\mathrm{B}$ induced by focal cerebral ischemia in Sprague-Dawley rats. Lab. Anim. Res. 31, 134-138. doi: 10. 5625/lar.2015.31.3.134

Signorini, C., Ciccoli, L., Leoncini, S., Carloni, S., Perrone, S., Comporti, M., et al. (2009). Free iron, total $F_{2}$-isoprostanes and total $F_{4}$-neuroprostanes in a model of neonatal hypoxic-ischemic encephalopathy: neuroprotective effect of melatonin. J. Pineal Res. 46, 148-154. doi: 10.1111/j.1600-079x.2008. 00639.x

Sinha, K., Degaonkar, M. N., Jagannathan, N. R., and Gupta, Y. K. (2001). Effect of melatonin on ischemia reperfusion injury induced by middle cerebral artery occlusion in rats. Eur. J. Pharmacol. 428, 185-192. doi: 10.1016/s00142999(01)01253-5

Slominski, R. M., Reiter, R. J., Schlabritz-Loutsevitch, N., Ostrom, R. S., and Slominski, A. T. (2012). Melatonin membrane receptors in peripheral tissues: distribution and functions. Mol. Cell. Endocrinol. 351, 152-166. doi: 10.1016/j. mce.2012.01.004

Song, J., Kang, S. M., Lee, W. T., Park, K. A., Lee, K. M., and Lee, J. E. (2014). The beneficial effect of melatonin in brain endothelial cells against oxygen-glucose deprivation followed by reperfusion-induced injury. Oxid. Med. Cell. Longev. 2014:639531. doi: $10.1155 / 2014 / 639531$

Sontag, E., Luangpirom, A., Hladik, C., Mudrak, I., Ogris, E., Speciale, S., et al. (2004). Altered expression levels of the protein phosphatase $2 \mathrm{~A} \mathrm{AB} \alpha \mathrm{C}$ enzyme are associated with Alzheimer disease pathology. J. Neuropathol. Exp. Neurol. 63, 287-301. doi: 10.1093/jnen/63.4.287

Sun, F.-Y., Lin, X., Mao, L.-Z., Ge, W.-H., Zhang, L.-M., Huang, Y. L., et al. (2002). Neuroprotection by melatonin against ischemic neuronal injury associated with modulation of DNA damage and repair in the rat following a transient cerebral ischemia. J. Pineal Res. 33, 48-56. doi: 10.1034/j.1600-079x.2002. 01891.x

Tang, Y., Cai, B., Yuan, F., He, X., Lin, X., Wang, J., et al. (2014). Melatonin pretreatment improves the survival and function of transplanted mesenchymal stem cells after focal cerebral ischemia. Cell Transplant. 23, 1279-1291. doi: 10. 3727/096368913x667510

Tan, D. X., Manchester, L. C., Terron, M. P., Flores, L. J., Tamura, H., and Reiter, R. J. (2007). Melatonin as a naturally occurring co-substrate of quinone reductase-2, the putative MT3 melatonin membrane receptor: hypothesis and significance. J. Pineal Res. 43, 317-320. doi: 10.1111/j.1600-079x.2007.00513.x

Toklu, H., Deniz, M., Keyer-Uysal, M., and Sener, G. (2009). The protective effect of melatonin and amlodipine against cerebral ischemia/reperfusion-induced oxidative brain injury in rats. Marmara Med. J. 22, 34-44.

Wakatsuki, A., Okatani, Y., Shinohara, K., Ikenoue, N., and Fukaya, T. (2001). Melatonin protects against ischemia/reperfusion-induced oxidative damage to mitochondria in fetal rat brain. J. Pineal Res. 31, 167-172. doi: 10.1034/j.1600079x.2001.310211.x

Yang, Y., Duan, W., Li, Y., Yan, J., Yi, W., Liang, Z., et al. (2013). New role of silent information regulator 1 in cerebral ischemia. Neurobiol. Aging 34, 2879-2888. doi: 10.1016/j.neurobiolaging.2013.06.008

Yang, Y., Jiang, S., Dong, Y., Fan, C., Zhao, L., Yang, X., et al. (2015). Melatonin prevents cell death and mitochondrial dysfunction via a SIRT1-dependent mechanism during ischemic-stroke in mice. J. Pineal Res. 58, 61-70. doi: 10. 1111/jpi.12193

Zhao, L., An, R., Yang, Y., Yang, X., Liu, H., Yue, L., et al. (2015). Melatonin alleviates brain injury in mice subjected to cecal ligation and puncture via attenuating inflammation, apoptosis and oxidative stress: the role of SIRT1 signaling. J. Pineal Res. 59, 230-239. doi: 10.1111/jpi.12254

Zivin, J. A., Fisher, M., DeGirolami, U., Hemenway, C. C., and Stashak, J. A. (1985). Tissue plasminogen activator reduces neurological damage after cerebral embolism. Science 230, 1289-1292. doi: 10.1126/science.3934754

Conflict of Interest Statement: The authors declare that the research was conducted in the absence of any commercial or financial relationships that could be construed as a potential conflict of interest.

Copyright (c) 2016 Romero, Ramos, Patiño, Oset-Gasque, López-Muñoz, MarcoContelles, Ayuso and Alcázar. This is an open-access article distributed under the terms of the Creative Commons Attribution License (CC BY). The use, distribution and reproduction in other forums is permitted, provided the original author(s) or licensor are credited and that the original publication in this journal is cited, in accordance with accepted academic practice. No use, distribution or reproduction is permitted which does not comply with these terms. 